Please share your stories about how Open Access to this article benefits you.

\title{
A Tale of Two Mam Children: Contact- Induced Language Change in Mayan Child Language
}

\author{
by Clifton L. Pye
}

2013

This is the published version of the article, made available with the permission of the publisher. The original published version can be found at the link below.

Clifton L. Pye. (2013). A Tale of Two Mam Children: Contact-Induced Language Change in Mayan Child Language. International Journal of American Linguistics 79(4).

Published version: http://www.dx.doi.org/10.1086/671775

Terms of Use: http://www2.ku.edu/ scholar/docs/license.shtml 


\title{
A TALE OF TWO MAM CHILDREN: CONTACT-INDUCED LANGUAGE CHANGE IN MAYAN CHILD LANGUAGE ${ }^{1}$
}

\author{
Clifton L. Pye \\ UNIVERSITY OF KANSAS
}

\begin{abstract}
Mayan languages have been in contact with Spanish for nearly 500 years and yet maintain much of their structural integrity. The arrival of bilingual schools and television has now altered the circumstance of language use within many Mayan households. This article compares children's and mothers' production of verb, existential, and negation constructions in Spanish and five Mayan languages, with a special focus on Mam. Mayan children may have vocabularies with up to $20 \%$ Spanish-derived lexemes and still not exhibit significant structural changes in their grammars. A two-year-old Mam child growing up with intense pressure to use Spanish exhibited changes to verb, existential, and negation constructions that were not evident in the language of other Mayan-speaking children. Verb use and negation appear to be especially sensitive indicators of such change. Contact-induced structural change shows how children's emerging grammars accommodate new structural elements.
\end{abstract}

[KeYwords: language shift, codeswitching, Mam, Maya, language acquisition]

1. Introduction. Research on language acquisition in stable multilingual societies shows that children are quite capable of sorting out the distinctive grammatical features of the languages they encounter and setting the parameters for each language appropriately (Grosjean 1982). Language acquisition research in communities undergoing language shift introduces a different set of concerns. Two-year-olds in such communities may decide to use just one of the languages that they hear at home, even though their

1 This project would not be possible without the efforts of the Mam investigators: Ana Elizabeth López Ramirez, Juana Isabel López Morales, Sheny Ortíz García, and Luis Hernandez López Ramirez; the Q'anjob'al investigators: Pedro Mateo Pedro, Flora García, Diego Martínez Esteban, Francisco Pedro Mateo, Pedro Martínez Esteban, Efraín Ramón de León, Basilio Luin Bernabé, and Basilio Sebastian Basilio; the Ch'ol investigators: Pedro Gutiérrez Sánchez, Asuncion López Pérez, Euripides Lopez Gutierrez, and Melba del Carmen Martínez Pérez; and the K'iche' investigators: Augustin Huix Huix, Pedro Quixtan Poz, Emilio Quiej Huix, and Santos Quiej Huix. Data collection for Mam, Q'anjob'al, and Ch'ol was funded by grants from the National Science Foundation (BCS-0613120 and BCS-0515120) and the General Research Fund of the University of Kansas (GRF-2301063). Data collection for K'iche' was supported by grants from the Organization of American States and the Wenner-Gren Foundation. The Teenek research is funded by CONACYT \#105596 (PI Barbara Blaha Degler Pfeiler). An earlier version of this paper was presented at the CILLA V conference at the University of Texas in Austin. I thank the participants for their comments and suggestions. I also thank an associate editor of this Journal as well as the reviewers for many helpful suggestions. I am solely responsible for any errors.

[IJAL, vol. 79, no. 4, October 2013, pp. 555-75]

(C) 2013 by The University of Chicago. All rights reserved.

0020-7071/2013/7904-0004\$10.00 
parents are less fluent in that language. Even when two-year-olds continue using both languages, their emerging grammars can provide evidence of contact-induced language change (Harris and Campbell 1995 and Winford 2003).

Despite decades of research on language shift and bilingual acquisition, few studies exist of children's emerging grammars in Native American communities undergoing language shift (Heinze 2004 and Pye 1992). Mayan languages have been in contact with Spanish for nearly 500 years and have borrowed many words including the connectives pero 'but' and $y$ 'and'. Despite the evident imbalance between indigenous languages and Spanish, large numbers of Mayan speakers in Mexico and Guatemala have preserved most of their languages until the present. The arrival of bilingual schools and television has now altered the circumstance of language use within many Mayan households.

Existing studies of bilingualism in Mayan communities are based on interviews with adolescent and adult speakers (Brown 1998, Collins 2005, and Garzon 1998). The Brown and Garzon studies established that Kaqchikel Maya communities relatively close to the Guatemalan capital demonstrate significant generational shifts in the use of Kaqchikel. Brown surveyed language use in 444 homes in the Quinizilapa Valley in Guatemala. He reported that half of the participants did not speak Kaqchikel with their children, and that over two-thirds of the valley households spoke Spanish to some degree. He concluded that "within two generations Kaqchikel will no longer be spoken in the valley" (Brown 1998:127).

While these studies provide invaluable information on the pace of language shift in Mayan communities, they do not assess where the structure of Kaqchikel has changed in the course of the shift from Kaqchikel to Spanish. The studies also did not analyze the language of two-year-old speakers. The studies do not show how a two-year-old establishes a linguistic identity in a multi-generational household using two or more languages. A final limitation of such studies is that they do not assess the degree to which their observations generalize to other Mayan language communities.

The data for this study were recorded as part of a longitudinal investigation of the acquisition of three Mayan languages. ${ }^{2}$ The longitudinal investigation

2 I present data from seven Mayan languages: Mam (ISO code: mam), K'iche' (ISO code: quc), Q'anjob'al (ISO code: kjb), Chontal (ISO code: chf), Ch'ol (ISO code: cti), Tojolab'al (ISO code: toj), and Teenek (Wastek) (ISO code: hus). Mam and K'iche' belong to the Eastern Mayan division of the language family. Both languages are spoken in the western highland region of Guatemala. Q'anjob'al belongs to the Q'anjob'alan branch of the western division of Mayan languages and is spoken in the western region of the Huehuetenango Department in Guatemala. Ch'ol and Chontal belong to the Ch'olan branch of the family. Ch'ol is spoken in the state of Chiapas, Mexico, and Chontal is spoken in the state of Tobasco, Mexico. The classification of Tojolab'al is problematic; Kaufman (1990) considers it to be part of the Q'anjob'alan branch. Tojolab'al is spoken in the eastern region of Chiapas, Mexico. Teenek, also referred to as Huastec 
recorded three children in each of three languages every two weeks between two and three years of age. Approximately 80 hours of recordings were made for children acquiring Ch'ol, Mam, and Q'anjob'al. These recordings were transcribed and the transcripts are available on the Almaya archive (almaya. org). The goal of this investigation was to obtain samples of children who were acquiring Mayan languages in monolingual households.

In the course of this project, the Mam investigator happened to record a child living in a mixed Mam-/Spanish-speaking household. This child's language environment and development are markedly distinct from those of all the other Mayan children who were recorded. The special circumstances of this recording provide a unique opportunity to explore how language contact can alter the grammar of children in Mayan-speaking communities. The recording provides a baseline for the investigation of language change among two-year-old Mayan children and informs language revitalization efforts in Mayan communities. The longitudinal database for Mayan monolingual children makes it possible to assess the impact of Spanish on specific grammatical constructions in each Mayan language. The study, thus, has important implications for research on contact-induced language change (see Gross 2000).

2. Indicators of contact-induced language change. I explore three linguistic features as indicators of contact-induced change in Mam: verbal predication, existential constructions, and negation. Each one of these constructions has distinct realizations in Spanish and Mam, which makes it possible to see where the grammar of Mam has been affected by contact with Spanish.

2.1. Verb predication. The structure of verbal predicates differs greatly between Mam and Spanish. Mam verbs have distinct inflections for aspect, subject, and object. Spanish verbs have a single suffix that marks the combination of subject agreement and tense. Mam incorporates Spanish nouns and verbs by adding an antipassive suffix to the infinitive form of Spanish verbs. For example, the verb skweelan 'go to school' is listed in the Mam dictionary (Maldonado Andrés, Ordóñez Domingo, and Ortiz Domingo 1986). ${ }^{3}$ This verb is derived by adding the antipassive suffix /-n/

or Wastek, is spoken in the states of Veracruz and San Luís Potosí, Mexico. Teenek belongs to its own branch of the Mayan language family.

${ }^{3}$ All Mam examples are shown in the practical orthography developed by the Proyecto Lingüístico Francisco Marroquín (Kaufman 1976) with a single exception: I use <'> rather than $<7>$ for the glottal stop. The other orthographic symbols have their standard IPA values except: $<\mathrm{tz}>=/ \mathrm{ts} /,<\mathrm{ch}>=/ \mathrm{t} \int /,<\mathrm{tx}>=/ \mathrm{ts} /,<\mathrm{b}^{\prime}>=/ \mathrm{b} /,<\mathrm{tz}^{\prime}>=/ \mathrm{ts}^{\prime} /,<\mathrm{ch}^{\prime}>=/ \mathrm{t} \int^{\prime} /,<\mathrm{tx}^{\prime}>=/ \mathrm{ts} \mathrm{e}^{\prime} /,<\mathrm{x}>=$ $/ \mathrm{s} /,<\mathrm{xh}>=/ \mathrm{f} /,<\mathrm{j}>=\mid \chi /,<\mathrm{ky}>=/ \mathrm{c} /$. Repeated vowels (e.g., $<\mathrm{aa}>$ ) indicate long vowels. I use the following abbreviations: 1 = first-person marker, 2 = second-person marker, 3 = third-person marker, 4 = first-person plural, $6=$ third-person plural; $\mathrm{ABS}=$ absolutive marker, $\mathrm{AP}=$ antipassive, 
TABLE 1

Discourse and Predicate Negation Particles in Mam

\begin{tabular}{lccccccc}
\hline \hline & & \multicolumn{2}{c}{ Existential } & & & & \\
\cline { 3 - 4 } Indicative & Potential & Human & Nonhuman & Stative & Imperative & Admonitive & Discourse \\
\hline miti'/nti' & mii'n & mi'aal & miti'/nti' & miyaa' & mii'n & qax & mii'n \\
\hline
\end{tabular}

to the root skweela, derived from the Spanish noun escuela 'school'. The use of the antipassive suffix on nouns and verbs borrowed from Spanish provides one measure of contact-induced change.

2.2. Existentials. Mayan existentials are used to express existence, location, and possession. As shown by the examples in (1), Spanish uses the verbs haber 'exist', estar 'be at', and tener 'have' to express the same concepts as the Mam existential. The Mam existential has different forms for different persons and moods. The Mam existentials for first, second, and third person are (a)tiina, (a)ta, and at respectively. In interrogative contexts, the Mam existential has the form jat, while in negative contexts with humans, it has the form mi'aal and in negative contexts with nonhumans, it has the form nti'. If Mam speakers switch to Spanish, the existential construction would be one domain which might indicate a change in language identity.

(1) Existential constructions in Mam

$\begin{array}{ll}\text { Existence } & \text { at pwaq } \\ & \text { exist money } \\ & \text { 'Hay dinero'. } \\ & \text { 'There is money'. }\end{array}$

Location at-a tzluu'

exist-ENC here

'Estás aquí'.

'You are here'. (England 1983:246)

$\begin{array}{llll}\text { Possession } & \text { at } & \text { juun } & n \text {-jaa-ya } \\ & \text { exist } & \text { one } & 1 \text { ABS-house-ENC }\end{array}$

'Tengo una mi casa'.

'I have a house'. (England 1983:147)

2.3. Negation. Mam has a complex system of negation. Whereas Spanish uses the particle no to mark negation in all discourse and predicate contexts, Mam uses a variety of negative particles to mark negation in different contexts (see table 1). England (1983:244) suggests that many of the Mam

$\mathrm{CMP}=$ completive aspect, $\mathrm{ENC}=$ enclitic, $\mathrm{ERG}=$ ergative marker, $\mathrm{INC}=$ incompletive aspect, $\mathrm{INF}=$ infinitive, $\mathrm{IMP}=$ imperative, $\mathrm{IV}=$ termination marker for intransitive verbs, $\mathrm{NEG}=$ negative marker, POSS $=$ possessive noun, PROG $=$ progressive, TS $=$ thematic suffix. 
negative particles are based on combinations of mii with other particles. I distinguish between discourse negation used in response to a yes/no question or command from predicate negation used to negate a predicate. I exclude determiner forms of negation such as nada and ningún, affixal, and lexical negation from this analysis. Negation is one area where it would be much easier to use the single Spanish particle no in place of the complex system of negative particles in Mam. Negation provides a precise indicator of the contexts in which the Spanish particle replaces the contrasts required in Mam.

\section{Method.}

3.1. Subjects. This article focuses on the language of two Mayan children living in the Mam-speaking community of San Ildefonso Ixtahuacán, Guatemala. This pilot study provides a detailed comparison of three grammatical constructions in the grammars of the children and their mothers and siblings, with the goal of identifying specific indicators of contact-induced changes in the grammars of children acquiring Mayan languages. The target children are both two years old and live in the same community. WEN's family uses Mam at home but can also use Spanish outside the home to a limited extent. The family speaks to their two-year-old daughter in Mam. NOR's family uses a mixture of Mam and Spanish at home and uses a mixture of the two languages in their speech to their two-year-old son. NOR has a four-year-old brother, MIG, who uses Spanish extensively and who exerts pressure on NOR to use Spanish as well. The two households provide a miniature laboratory for an exploration of how grammatical constructions from Spanish enter the emerging grammars of two-year-old speakers.

3.2. Procedure. The language of WEN and NOR as well as their mothers and siblings provides the data for this study. I extracted all of the utterances that these two pairs of mothers and children produced in the course of a one-hour recording session. The same Mam investigator was present in both sessions and spoke only Mam during the recording. I divided the utterances and words produced by the mothers and children into Mam and Spanish forms.

3.3. Spanish and Mam. The distinction between Spanish and Mam is not exact. Some Spanish words are thoroughly integrated into the grammar of Mam, i.e., borrowing, while other Spanish words enter by switching from Mam to Spanish, i.e., codeswitching. I used a conservative criterion for assigning words to these languages since Mam has borrowed many words from Spanish over the course of five centuries. The borrowed words exhibit different degrees of integration into Mam, defined by their phonological and morphological features. For example, the word wakxh (<Sp. vaca 'cow') 
has been fully integrated into Mam's phonology. I counted this word as a Mam word. I decided that the word reloj (< Sp. reloj 'wristwatch') has not been integrated to the same extent and so counted reloj as a Spanish word.

The Spanish words fall into several categories. I counted the exclamations ay, baya, and oh as Spanish. I counted names such as Ana and Miguel as Spanish but counted names with phonological changes such as Mak $(<\mathrm{Sp}$. Marcos) as Mam. I counted all forms of mamá and papá (e.g., mami, mam, papi) as Spanish, even though many Mayan families use these words at home. These decisions also affected the number of utterances that I counted as Spanish because the children produced many one-word utterances containing the names of individuals. I counted Spanish words with Mam possessive prefixes and enclitics, e.g., $t$-caballito-ya (2ERG-caballito-ENC 'your horsey') as Mam because the inflections indicate their integration into the grammar of Mam.

I counted all utterances with Mam predicates as Mam, even if they included an argument that was Spanish, e.g., q'i'tz t-caballito chux ('anda_traer tucaballito bueno', 'go_get your-horsey good'). I used the same rule for nonverbal predicates such as jat papá? ('donde está papá?' 'where is dad?'). Utterances such as patearana pelota ('patea la pelota', 'kick the ball') create obvious problems for a simple division between Mam and Spanish utterances. In this case, the verb borrowed from Spanish has the Mam suffix -ana attached to the Spanish infinitive form patear, so I counted it as a Mam utterance.

Utterances produced by two-year-old children create unique difficulties in distinguishing between borrowing and codeswitching. My analysis of the children's words relies on the interpretations of the children's utterances by native speakers of Mam. I stated above that I relied on phonology to distinguish between Mam and Spanish words. The words produced by two-year-old children commonly omit many sounds in their speech. NOR produced the Spanish word camión 'truck' as /kayon/, /nyon/, and /ton/. WEN produced pato 'duck' as /pat/ and pelota 'ball' as /yot/. I counted these productions as attempts to produce Spanish words because these phonological changes display typical examples of unstressed syllable reduction and liquid-to-glide substitution documented for the Mayan language K'iche' (see Pye, Ingram, and List 1987). ${ }^{4}$ Many researchers rely on morphological inflections to make such a distinction. Two-year-old children frequently omit morphological inflections, which makes the decision to count their utterances as Mam or Spanish more difficult.

\footnotetext{
${ }^{4}$ I thank Cecilia Rojas Nieto for bringing to my attention that children acquiring Spanish commonly reduce words to a trochaic foot, producing the word zapato 'shoe' as /pato/ and pelota 'ball' as /tota/. The Mam children's production of these words is more in keeping with the CVC structure of Mam roots. I have not included syllable structure in my analysis for this article.
} 
TABLE 2

Basic Statistics for Mam Mothers and Children

\begin{tabular}{|c|c|c|c|c|c|c|}
\hline & \multirow[b]{2}{*}{ Age } & \multicolumn{2}{|c|}{$\begin{array}{l}\text { Number of } \\
\text { Utterances }\end{array}$} & \multicolumn{2}{|c|}{ Number of Words } & \multirow{2}{*}{$\begin{array}{l}\text { MLU in } \\
\text { Words }\end{array}$} \\
\hline & & Total & Spanish & Total & Spanish & \\
\hline \multicolumn{7}{|l|}{ Children: } \\
\hline WEN & $2 ; 1.7$ & 849 & $27(3 \%)$ & 327 & $35(11 \%)$ & 1.41 \\
\hline NOR & $2 ; 1.28$ & 380 & $148(39 \%)$ & 112 & $58(50 \%)$ & 1.37 \\
\hline MIG & $4 ; 5$ & 600 & $518(86 \%)$ & 264 & $225(85 \%)$ & 1.87 \\
\hline \multicolumn{7}{|l|}{ Mothers: } \\
\hline WEN & & 731 & $25(3 \%)$ & 317 & $24(8 \%)$ & 3.47 \\
\hline NOR & & 272 & $39(14 \%)$ & 299 & $94(31 \%)$ & 3.66 \\
\hline
\end{tabular}

4. Results. Table 2 provides basic measures of language use in these two families. Table 2 includes statistics for NOR's four-year-old brother, MIG, who speaks Spanish predominantly.

All of the speakers incorporated elements of Spanish into their speech to some extent. WEN's frequency of Spanish words and utterances matches that of her mother and typifies the speech of monolingual Mayan speakers, as I show below. NOR's mother incorporates a higher percentage of Spanish words and phrases into her speech and illustrates the frequencies that are produced by a bilingual speaker interacting with other speakers who only use Mam. NOR's frequency of Spanish words and utterances reflects the pressure that he receives from his four-year-old brother MIG to use Spanish. MIG's frequency of Spanish words and utterances far exceeds those frequencies for the other speakers shown in table 2. MIG considers himself to be a Spanish speaker and exerts pressure on his younger brother to speak Spanish, as shown in the dialogue in (2). Spanish words are shown in boldface italics in all examples.

(2) Dialogue between mother, NOR, and MIG

Mother: mi'n chi.

no say

'He said no'.

MIG: en castillano decile.

'Say it to her in Spanish'.

MIG: $\quad$ no decile.

'Say "no" to her'.

NOR: no.

This dialogue occurred in a context in which the Mam investigators were attempting to elicit speech from NOR in Mam, while ignoring MIG's interruptions. MIG attempted to gain attention by acting as an intermediary and interpreter for NOR. The dialogue in (2) shows that MIG understands Mam 
but thinks that his brother NOR does not. He helps his brother by translating Mam into Spanish and by interpreting his brother's utterances for the adults. MIG also speaks more often than any of the other participants, and provides a background narrative in Spanish throughout the session. Later in the session, NOR's mother offers the following explanation for MIG's language behavior:

(3) Explanation of MIG's language

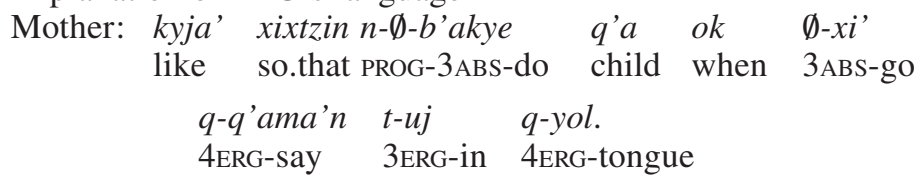

'That is what they do when we speak to them in Mam'.

Mother: pera mal kin n-Ø-q'ama'n t-e.

but that little_one PROG-3ABS-say 3ERG-POSS

'But that is what he says'.

WEN's and NOR's households present distinct language profiles. WEN's family is a typical monolingual household that uses Mam on most occasions, although they understand Spanish. NOR lives in a divided household in which his mother is a monolingual Mam speaker and his brother is a monolingual Spanish speaker. ${ }^{5}$ As the youngest member of his family, NOR is in a position where he must constantly negotiate between the language demands of Mam and Spanish.

4.1. Verb predication. I analyzed the Spanish-derived verbs that the speakers used in their sessions for evidence of the use of the Mam antipassive. The Spanish-derived verbs that the speakers produced are shown in table 3. WEN is not included in this table because she did not produce any Spanish verbs.

The Spanish-derived verbs produced by these speakers indicate a clear division between the Mam speakers and bilingual speakers who have incorporated more Spanish into their speech. WEN's mother produced three Spanishderived verbs and all three were inflected with the Mam antipassive suffix. NOR's mother produced 19 Spanish-derived verbs and only one was inflected with the antipassive suffix. Examples of the mothers' Mam-inflected verbs are shown in (4). NOR's mother produced many Mam verbs with equivalent meanings. The discourse context rather than her ability to speak Mam determined when she produced the Spanish verbs.

\footnotetext{
5 MIG's behavior is typical of bilingual children who identify speakers with specific languages. Grosjean (1982:198-99) reviews a number of examples of bilingual children who insisted that their interlocutors use a single language. Henrik, a French-German bilingual child described in Redlinger and Park (1980), would not speak to a bilingual investigator in French, and he translated his mother's French utterances into German for the sake of the investigator.
} 
TABLE 3

Spanish-Derived Verbs Produced by Mam Speakers

\begin{tabular}{|c|c|c|c|c|c|c|c|}
\hline \multicolumn{2}{|c|}{ WEN's Mother } & \multicolumn{2}{|c|}{ NOR's Mother } & \multicolumn{2}{|c|}{ NOR } & \multicolumn{2}{|c|}{ MIG } \\
\hline Type & Tokens & Type & Tokens & Type & Tokens & Type & Tokens \\
\hline skweelan & 2 & andar & 2 & dar & 1 & agarrar & 5 \\
\hline llamaran & 1 & dar & 2 & hay & 1 & alcanzar & 2 \\
\hline \multirow[t]{39}{*}{ chichina } & 1 & hacer & 1 & meter & 1 & andar & 1 \\
\hline & & hay & 1 & tirar & 2 & apurar & 21 \\
\hline & & ir & 2 & venir & 2 & cachar & 5 \\
\hline & & jugar & 5 & & & caer & 2 \\
\hline & & llevar & 1 & & & caminar & 1 \\
\hline & & mirar & 1 & & & contestar & 2 \\
\hline & & patear & 2 & & & dar & 23 \\
\hline & & patearana & 1 & & & decir & 22 \\
\hline & & poner & 1 & & & dejar & 2 \\
\hline & & quedar & 1 & & & empujar & 1 \\
\hline & & querer & 1 & & & esperar & 2 \\
\hline & & saber & 1 & & & estar & 16 \\
\hline & & salir & 1 & & & ganar & 2 \\
\hline & & ser & 1 & & & hacer & 1 \\
\hline & & tocar & 1 & & & hay & 12 \\
\hline & & traer & 2 & & & ir & 47 \\
\hline & & ver & 1 & & & jugar & 9 \\
\hline & & & & & & levantar & 1 \\
\hline & & & & & & llegar & 1 \\
\hline & & & & & & meter & 3 \\
\hline & & & & & & mirar & 68 \\
\hline & & & & & & parecer & 2 \\
\hline & & & & & & pegar & 1 \\
\hline & & & & & & poner & 16 \\
\hline & & & & & & querer & 1 \\
\hline & & & & & & quitar & 4 \\
\hline & & & & & & recibir & 2 \\
\hline & & & & & & recojer & 1 \\
\hline & & & & & & saber & 2 \\
\hline & & & & & & sacar & 1 \\
\hline & & & & & & salir & 2 \\
\hline & & & & & & ser & 24 \\
\hline & & & & & & soltar & 1 \\
\hline & & & & & & tener & 9 \\
\hline & & & & & & tirar & 7 \\
\hline & & & & & & tomar & 1 \\
\hline & & & & & & traer & 2 \\
\hline & & & & & & venir & 7 \\
\hline & & & & & & ver & 2 \\
\hline Totals: 3 & 4 & 19 & 28 & 5 & 7 & 41 & 334 \\
\hline
\end{tabular}


(4) Mam-inflected Spanish-derived verbs in the mothers' speech

(4a) WEN's mother

n-chi skweela-n b'ixh chikiya.

PROG-6ABS study-AP they say_it

'ellas están estudiando dígale'.

'Tell her they are studying'.

(4b) NOR's mother

patear-an-a pelota.

kick-AP-ENC pelota

'patea la pelota'.

'Kick the ball'.

MIG's verb production is clearly different from the mothers' speech. He produced 41 different Spanish verbs without adding the Mam antipassive suffix to any of them. He also produced a few Mam verbs, again demonstrating that he can speak in Mam when necessary. WEN did not produce any Spanish verbs, while NOR produced five Spanish verbs. NOR did not produce any examples of a Spanish verb with the Mam antipassive suffix. One of his Spanish verb utterances occurred in the complex sentence shown in (5). In this example, NOR uses the Spanish verb venir 'come' in place of the Mam directional verb tzaj. In the Spanish construction, the directional verb is followed by the preposition $a$, while in the Mam construction, the directional has the second-person enclitic /-a/. The interpretation of the $<a>$ as the Spanish preposition is more likely since Mam normally inserts an epenthetic glide with the enclitic after a verb which ends in a vowel, e.g., venga-y-a. However, in Spanish, the final vowel of venga and the vowel of the preposition would normally contract to a single vowel. There is a clear gap between the vowels in NOR's production.

(5) NOR

venga a beta. = venga a beta-l. (Mam: tzaj-a beta-l)

venga a caminar-INF

'Come walk'.

4.2. Existentials. I produced lexical concordances for each of the mothers and children, which list all of the words with their context of use that a speaker produced. From these concordances, I extracted all of the utterances that contained the Mam existential words at, tiina, ata, jat, mi'aal, and nti', as well as the Spanish words hay, estar, and tener. As shown in table 4, NOR and his mother each produced a Spanish existential construction, while WEN and her mother did not. NOR's brother produced far more Spanish existential constructions than the other speakers, but even he 
TABLE 4

Number of Existential Constructions

(Percentage of Total Utterances) in Mam and Spanish

\begin{tabular}{lccc}
\hline \hline & Mam Existentials & Spanish Existentials & Total Utterances \\
\hline NOR's mother & $8(3 \%)$ & $1(0 \%)$ & 272 \\
NOR & $8(2 \%)$ & $2(1 \%)$ & 380 \\
MIG & $3(1 \%)$ & $33(6 \%)$ & 600 \\
WEN's mother & $39(5 \%)$ & & 731 \\
WEN & $10(1 \%)$ & & 849 \\
\hline
\end{tabular}

produced three existential constructions in Mam. Examples of the children's existential constructions in Mam and Spanish are shown in (6).

(6) Children's existential utterances

(6a) WEN

at $\quad w e^{\prime} .=$ at $w$-e-ky'.

exist 1ERG-POSS-ENC

'yo tengo'.

'I have it'.

(6b) NOR

ata $\quad m u .=$ at $m u$.

exist mu

'hay mu (cow)'.

'There's a moo'.

(6c) NOR

nay yata. = no hay llanta.

'There's no tire.'

MIG and the two mothers produced existential constructions in $6 \%$ of their utterances. This equivalence serves as a rough indicator that the contexts of the recordings were similar for the two children. NOR and his mother both produced Spanish existential constructions, while WEN and her mother produced only existential constructions in Mam. The Spanish existentials that NOR and his mother produced were all negative with nonhuman arguments. NOR and his mother also produced negative existentials with nonhuman arguments in Mam, so there is evidence that both mother and son were aware of the Mam constructions and could use them. MIG produced both affirmative and negative existential constructions in Spanish. The fact that NOR and his mother produced existential constructions in Spanish indicates that they had made the change to bilingualism. The restricted use of these constructions to negate the existence of nonhuman arguments possibly marks an initial step in the change from Mam to Spanish. 
TABLE 5

Mam and Spanish Forms of Negation in Recordings

\begin{tabular}{|c|c|c|c|c|c|c|}
\hline Speaker & $\begin{array}{c}\text { Indicative } \\
n t i\end{array}$ & $\begin{array}{c}\text { Potential } \\
m i ' n\end{array}$ & $\begin{array}{c}\text { Existential } \\
\text { Nonhuman } \\
n t i\end{array}$ & $\begin{array}{l}\text { Stative } \\
\text { miyaa' }\end{array}$ & $\begin{array}{c}\text { Imperative } \\
m i ' n\end{array}$ & $\begin{array}{c}\text { Discourse } \\
m i i ' n\end{array}$ \\
\hline NOR's mother & & mi'n 6; no 2 & $n t i$ ' 9; no 1 & nya' 1 & mi’n 6 & mi’n 8; no 2 \\
\hline NOR & nada 2 & & nti' 4; no 2 & nya' 1 & & mi'n 2; no 34 \\
\hline MIG & no 8 & mi'n 2; no 6 & $n t i ' 2 ;$ no 5 & no 1 & no 2 & mi'n 1 ; no 22 \\
\hline WEN's mother & & mi’n 1 & $n t i ’ 4$ & nya' 3 & & mi'n 6 \\
\hline WEN & & & nada 1 & nya' 2 & & mi'n 7; no 2 \\
\hline
\end{tabular}

4.3. Negation. To analyze negation, I returned to the concordances of the mothers and children and extracted all of the negative utterances that the speakers produced in Mam and Spanish. Table 5 shows the Mam and Spanish forms of negation that the speakers produced in each context. The results show that all of the speakers produced a variety of negative particles in Mam. The two adults and WEN produced a majority of their negations in Mam; NOR produced many discourse responses with Spanish no. MIG produced Spanish negation forms in all of the contexts. WEN's and NOR's negation was restricted to fewer contexts than the mothers'. I provide examples of the children's negative utterances in (7).

(7) Children's negative utterances

(7a) WEN

ya ixhjH. = nyaa isja.

NEG papa

'It isn't a potato'.

(7b) NOR

ntit jHa. $=$ nti't ja'la.

NEG now

'There isn't any now'.

(7c) NOR

mami no hay pixht. = mami no hay pisto.

'Mama, there isn't any money'.

The children's use of the Spanish word nada 'nothing' is striking in comparison with the mothers' negative forms. Examples of the children's utterances with nada are shown in (8). WEN produced nada in the context of existential negation. The interpretation is not completely clear, but her use of nada is interpreted as a nonverbal stative predicate. Her use of nada does not occur in a verbal context. 
(8) Children's nada utterances

(8a) WEN

naa jH. = nada ja'la.

nothing now

'There isn't any now'.

(8b) NOR

ata $\quad$ tan. $^{6}=$ nada $n$ - $\emptyset$-tan. $\quad($ Mam: nti' $n$ - $\emptyset$-tan $)$

nothing PROG-3ABS-sleep

'S/he is not sleeping'.

NOR produced nada in the context of indicative negation. His production also substitutes nada for the Mam form nti' but does so in a verbal context. He regularly substitutes / $/$ for /d/, so there is independent evidence for this interpretation. He produced $n t i$ ' as /ntit/, shown above in $(7 b)$. NOR produced $n t i$ ' in the context of existential negation but substituted nada in the indicative context. WEN did not produce the Mam negative particle $n t i$ '.

The context of negation provides a more complex domain for the entry of Spanish forms into the grammar of Mam. NOR's and his mother's use of Spanish no in the context of existential and potential negation distinguishes their speech from that of WEN and her mother. Although NOR and his mother use the Mam negation particles in these contexts, their use of Spanish no indicates the spread of Spanish constructions into traditional Mam negation contexts. MIG's use of Spanish no is more extreme than that of NOR and his mother. MIG still produced a few forms of negation in Mam, and he made the appropriate choices for the context of negation for the Mam forms. MIG's Mam forms of negation show that he can speak in Mam if he wishes, but that he prefers to speak in Spanish.

I conclude that negation provides a sensitive indicator of the entry of Spanish into the speech domains of Mam. The form of discourse negation appears to be an especially sensitive indicator of Spanish use. NOR and MIG produce Spanish negation in discourse contexts far more frequently than the other speakers.

4.4. Summary of results. I surveyed three linguistic constructions for evidence of Spanish intrusions. Table 6 provides a summary of these

${ }^{6}$ An alternative analysis of this example would interpret ata as the second- or third-person existential yielding 'there is sleep'. The adult grammar does not use the existential in this manner, which makes the affirmative existential interpretation unlikely. Another possibility would be to interpret ata as an attempt to produce the negative existential nti'. The adult grammar uses the negative existential to negate verbal predicates, and so this is a possible interpretation that would be in keeping with the Mam form nti' $n$ - Ø-tan 's/he is not sleeping'. There is no other instance of confusion between affirmative and negative forms of the existential in the children's data, so this interpretation also seems less likely than the interpretation as nada. 
TABLE 6

Summary of Spanish Usage by Four Mam Speakers

\begin{tabular}{lccccc}
\hline \hline & WEN & WEN's Mother & NOR & NOR's Mother & MIG \\
\hline Spanish existentials & & & 2 & 1 & 33 \\
Contexts with $n o$ & 1 & & 2 & 3 & 6 \\
Spanish verbs & & & 5 & 18 & 41 \\
Spanish utterances & $3 \%$ & $3 \%$ & $39 \%$ & $14 \%$ & $86 \%$ \\
Spanish words & $11 \%$ & $8 \%$ & $50 \%$ & $31 \%$ & $85 \%$ \\
\hline
\end{tabular}

results. In each case, there is evidence that NOR and his mother produce more Spanish forms than WEN and her mother. MIG has the profile of a Spanish speaker. The linguistic analyses add a qualitative perspective to the quantitative comparisons based on the number of Spanish words and utterances the speakers produced. The linguistic analyses demonstrate how Spanish is entering Mam in specific grammatical contexts. Language change is frequently portrayed as either a wholesale replacement of a language or the widespread use of nouns and verbs from the intruding language. The results from Mam show how Spanish existentials and negation are used in conjunction with the more frequent use of unmodified Spanish verbs. The results also show that monolingual Mam speakers may use 10\% or more words borrowed from Spanish without making significant changes to the grammar of Mam.

NOR is clearly at a point where he is deciding between a linguistic identity like that of his mother or the linguistic model of his older brother. Although his use of Spanish is not as robust as that of his brother, he is using Spanish vocabulary and grammatical constructions much more frequently than WEN and her mother.

5. The acquisition of other Mayan languages. Up to this point, I have focused on the entry of Spanish into Mam. We do not know if Spanish enters the other Mayan languages in a similar fashion. The grammatical structure of each Mayan language could have significant effects on the incorporation of Spanish elements. One example of such structural differences is the incorporation of Spanish nouns and verbs. Mam incorporates Spanish nouns and verbs by adding the antipassive suffix. K'iche' incorporates Spanish nouns and verbs by means of a complex construction based on the K'iche' verb -b'an 'hacer' (9). Furbee (2000:101) provides an example of the same construction in Tojolab'al incorporating the Spanish noun perdón (10).

(9) K'iche'

$\begin{array}{lll}x-\emptyset-i m-b \text { 'an } & \text { engañar lee } & \text { achi. } \\ \text { CMP-3ABS-1ERG-do } & \text { engañar el hombre }\end{array}$

'I deceived the man'. (Mondloch 1978:117) 
(10) Tojolab'al

k'ulan perdón

do perdón

'pardon' (Furbee 2000:101)

The addition of an antipassive suffix, as in Mam, or the use of an auxiliary verb, as in K'iche' and Tojolab'al, illustrates two approaches that Mayan languages take to incorporating Spanish words. The Ch'ol example in (11) converts the Spanish noun dios 'god' to a verb and then adds an /-n/ suffix to the verb, while the Chontal example in (11) uses the auxiliary verb -chen 'hacer' with the Spanish verb inyectar 'inject'. Yucatec incorporates Spanish verbs by adding the active intransitive verb suffix to intransitive Spanish verbs (Barbara Pfeiler, personal communication). A study of each Mayan language is needed to document how these languages incorporate Spanish verbs and other grammatical elements into their grammars. This comparison would provide unique information about the structure of the Mayan languages that is not available by focusing on the Mayan elements alone. Such a study would provide the necessary background for studies of language change in Mayan-speaking communities.

(11a) Ch'ol

mi' diosi-n dioste'

INC dios-AP idol

'Él adora a un ídolo'.

'S/he adores an idol' (Aulie and de Aulie 1978:43)

(11b) Chontal de Tabasco

$\begin{array}{llllll}c h ' a '-i & y^{\prime} i & u k^{\prime} a & k \ddot{a} & \text { chen-et inyecta } \\ \text { lay_down-IMP } & \text { there } & \text { so } & \text { 1ERG } & \text { do-2ABS inyectar }\end{array}$

'Acuéstate ahí para que te inyecte'.

'Lay down so I can inject you'. (Keller and Luciano G. 1997:86)

The differences in strategies for incorporating Spanish nouns and verbs in the adult Mayan grammars suggest that children acquiring different Mayan languages may also incorporate Spanish elements into their grammars differently. I surveyed the use of Spanish existential and negation marking in recordings of two-year-old children acquiring four other Mayan languages to ascertain the degree to which the Mam results extend to these languages. The recordings were made in the course of a larger project documenting the acquisition of Mam, Q'anjob'al, and Ch'ol. The Teenek (Wastek) data come from Barbara Pfeiler's project documenting the acquisition of Teenek. For present purposes, I extracted data from the sessions, as shown in table 7.

Table 8 provides the basic statistics for each child, including the two Mam children. I applied the same criteria I used for Mam to decide, for each language, whether to count the words and utterances as Spanish or as Mayan. 
TABLE 7

Mayan Files in Analysis

\begin{tabular}{lll}
\hline \hline Language & Child & \multicolumn{1}{c}{ File } \\
\hline Mam & WEN & MW130207 \\
Mam & NOR & ME290905 \\
K'iche' & TIY & KT260577 \\
Q'anjob'al & XHUW & QA070607 \\
Ch'ol & EMA & CE240306 \\
Teenek & ANG & TA240610 \\
\hline
\end{tabular}

TABLE 8

Basic Statistics for Mayan Children

\begin{tabular}{|c|c|c|c|c|c|c|c|}
\hline \multirow[b]{2}{*}{ Children } & \multirow[b]{2}{*}{ Age } & \multirow[b]{2}{*}{ Language } & \multicolumn{2}{|c|}{$\begin{array}{l}\text { Number of } \\
\text { Utterances }\end{array}$} & \multicolumn{2}{|c|}{$\begin{array}{c}\text { Number of } \\
\text { Words }\end{array}$} & \multirow{2}{*}{$\begin{array}{l}\text { MLU in } \\
\text { Words }\end{array}$} \\
\hline & & & Total & Spanish & Total & Spanish & \\
\hline WEN & $2 ; 1.7$ & Mam & 849 & $27(3 \%)$ & 327 & $35(11 \%)$ & 1.41 \\
\hline NOR & $2 ; 1.28$ & Mam & 380 & $148(39 \%)$ & 112 & $58(50 \%)$ & 1.37 \\
\hline TIY & $2 ; 1.17$ & K'iche' & 559 & $6(1 \%)$ & 131 & $4(3 \%)$ & 1.07 \\
\hline XHUW & $2 ; 1$ & Q'anjob'al & 755 & $90(12 \%)$ & 232 & $25(11 \%)$ & 1.54 \\
\hline EMA & $2 ; 0.17$ & Ch’ol & 193 & $24(12 \%)$ & 128 & $22(17 \%)$ & 1.58 \\
\hline ANG & $2 ; 8.6$ & Teenek & 278 & $52(19 \%)$ & 162 & $30(19 \%)$ & 1.75 \\
\hline
\end{tabular}

The basic statistics for the children suggest that the Mam child, NOR, is the only child who produced a significantly higher proportion of Spanish words and utterances. The proportion of Spanish words that the Teenek child, ANG, produced is less than half that of NOR. The other children produced comparatively few Spanish words and utterances. The Q'anjob'al child, XHUW, produced a high number of Spanish words and utterances but is now a fluent speaker of Q'anjob'al and also has an excellent command of Spanish. The K'iche' child, TIY, produced the lowest proportion of Spanish words and utterances. I recorded TIY in the late seventies, so it is possible that her low rate of Spanish production reflects changes to Mayan speech patterns that have taken place over the past three decades.

I used concordances extracted from these files to analyze the children's use of Spanish existentials, negation, and verbs. These results are shown in table 9. Most of the children produced at least one of these constructions in Spanish. Despite the striking differences between the children in their proportion of Spanish words, their proportions of Spanish verbs, existentials, and negation do not differ greatly.

A closer look at the children's use of Spanish verbs, existentials, and negation tells a different story. NOR, EMA, and ANG were the only children who produced Spanish verbs. WEN, TIY, and XHUW did not, apart from the 
TABLE 9

Number (Percentage) of Spanish Constructions for Six Mayan Children

\begin{tabular}{lllcccc}
\hline \hline Children & Age & Language & Existential & Negation & $\begin{array}{c}\text { Spanish } \\
\text { Verbs }\end{array}$ & $\begin{array}{c}\text { Total } \\
\text { Utterances }\end{array}$ \\
\hline WEN & $2 ; 1.7$ & Mam & & $0(0 \%) / 2(0 \%)$ & & 849 \\
NOR & $2 ; 1.28$ & Mam & $2(1 \%)$ & $4(1 \%) / 34(9 \%)$ & $4(1 \%)$ & 380 \\
TIY & $2 ; 1.17$ & K'iche' & & $0(0 \%) / 5(1 \%)$ & & 559 \\
XHUW & $2 ; 1$ & Q'anjob'al & $2(0 \%)$ & $0(0 \%) / 4(1 \%)$ & & 755 \\
EMA & $2 ; 0.17$ & Ch'ol & $1(1 \%)$ & $0(0 \%) / 1(1 \%)$ & $1(1 \%)$ & 193 \\
ANG & $2 ; 8.6$ & Teenek & & $0(0 \%) / 11(4 \%)$ & $2(1 \%)$ & 278 \\
\hline
\end{tabular}

Spanish existential verbs, which I treat separately. The Ch'olan child EMA's production is ambiguous (12). The phonetic form [eñ] was glossed as ven 'come', but it could also be a repetition of the noun nene 'baby'.

(12) Ch'ol Spanish verb production

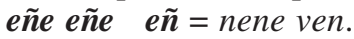

baby come

'Come baby'. (EMA)

The Teenek child ANG produced two Spanish verbs in single-word utterances: mira 'look' and voy 'I go'. Neither EMA nor ANG repeated their productions of these verbs, and no other Mayan child combined a Spanish verb with a Mayan word as did the Mam child NOR. NOR's production of a Spanish verb with a Mayan complement (8) is unique.

The children's use of Spanish existential verbs is more difficult to assess. The Spanish existential hay 'exist' has to be distinguished from the exclamation ay. The Q'anjob'al existential ay has the same phonetic form as the Spanish existential hay as well as the exclamation ay. The Q'anjob'al child XHUW produced 28 utterances containing the phonetic form [ay]. Thirteen of her productions were ambiguous. They occur in contexts in which both Q'anjob'al and Spanish use the form [ay] (13). I did not count these productions in table 9.

(13) Ambiguous existential production in Q'anjob'al ay xhik. = ay sik.

'hay frio'.

'It is cold'. (XHUW)

The other 13 of XHUW's productions with the form [ay] occurred in contexts that were unambiguously Q'anjob'al. Examples such as the one shown in (14) clearly indicate that the Q' anjob'al child is producing a Mayan existential construction. In this context, it is more common to claim that someone or something has an ear rather than to claim that there is an ear. The Spanish translation has the verb tener 'have' rather than the Spanish existential hay. 
(14) Q'anjob'al existential

ay tikan. $=$ ay txikin.

exist ear.

'S/he has an ear'. (XHUW)

I only included unambiguous examples of Spanish existential constructions that the children produced in table 9. Both of XHUW's productions used versions of the Spanish verb estar (15). She did not produce any negative existential utterances in Spanish.

(15) Spanish existential Q'anjob'al ta nene'. = donde está nene.

'Where is it baby?' or 'Where is the baby?' (XHUW)

Negation provides the best examples of Spanish influence on the children's grammars. The discussion of negation in Mam showed a difference between the use of the Spanish marker no in discourse contexts, such as in responses to yes/no questions and commands, and its use in other contexts, such as in existential constructions. Table 9 shows the number of times the children used Spanish negation forms in sentence and discourse contexts. Five of the six children produced negative sentences, and all five children used the Spanish marker no in discourse contexts. The examples in (16) show the K'iche' and Teenek children's use of Spanish negation in discourse contexts.

(16) Spanish discourse negation in K'iche' and Teenek

(16a) K'iche'

no', at oh. =no', at $x$-at-ya'-ow-ik.

no 2 ABS CMP-2ABS-give-AP-IV

'No, you gave it'. (TIY)

(16b) Teenek

no ma, kumaa'. = no mamá, ka um-a'.

no mama 2ERG grab-TS

'no mama, grab it'. (ANG)

The K'iche' child only used the Spanish negation no in discourse contexts. She used the K'iche' negation marker $m a$. . taj in all other contexts. The Teenek child, ANG, displayed the same use of negation. He only used the Spanish form no in discourse contexts $(16 b)$. He only used Teenek forms to mark negation in sentence contexts (17).

(17) Teenek negation in sentential context

nix yabaak? = nixee' yab-aak?

that NEG-still

'Isn't it still that?' (ANG) 
The Q'anjob'al analysis is more complex. The noun classifier for animals in Q'anjob'al has the same form as the Spanish negation marker no. The contexts of XHUW's use of the particle no indicate that she frequently used it as a noun classifier. In a few contexts, XHUW responded with the single word no, and in these cases, it is possible that she was producing the Spanish negation marker rather than the Q'anjob'al noun classifier. The example in (18) shows one of her productions of Spanish negation in a discourse context. XHUW only produced Spanish negation in discourse contexts.

(18) Spanish negation in Q'anjob'al

no nene'.

'no nene'.

'no baby'. (XHUW)

The Mam child, WEN, displayed a pattern of negation that is the same as the K'iche', Q' anjob'al, and Teenek children. She only used the Spanish form no in discourse contexts. She produced the Spanish negative pronoun nada 'nothing' as a lexical form ( $8 a$ above) rather than as a marker of sentential negation as NOR does $(8 b)$. NOR is the only child that extended Spanish negation to contexts of sentential negation. In this sense, negation appears to be an especially sensitive indicator of grammatical change. While the use of Spanish negation in discourse contexts lies outside of basic clause structure, the use of Spanish negation in existential and sentential contexts marks a qualitative change in the internal organization of the clause.

6. Conclusion. Mayan languages have been in contact with Spanish for nearly 500 years and yet have maintained much of their structural integrity throughout this period. The long period of contact has contributed many Spanish lexical items to Mayan vocabularies as well as exclamations and sentence connectives. Mayan languages have developed two distinct strategies for incorporating Spanish nouns and verbs using either an antipassive derivation or a light verb 'do' or 'give'. There are indications that this linguistic balance has changed in the past decade and that several Mayan languages will soon be lost. Children growing up in such circumstances may experience unusual situations of language acquisition, as documented in this article. These situations provide a unique window into a child's reconciliation of competing grammatical structures and provide invaluable evidence for the potential range of contact-induced syntactic change.

In addition to the vocabulary and verb use, this article examined children's forms of existential verbs and negation with a focus on two children growing up in a Mam community. The existential and negation constructions differ significantly between the Mayan languages and Spanish. These differences make it impossible for a bilingual speaker to simply transfer the Spanish 
forms to a Mayan language. Mayan existential constructions are translated by three Spanish verbs, while Spanish has a single form of negation that is translated by a variety of Mayan expressions. Such differences make it possible to observe how the Spanish forms replace Mayan forms in specific contexts.

A comparison of children acquiring five different Mayan languages showed that Mayan children growing up in monolingual or stable bilingual households may have vocabularies with up to $20 \%$ Spanish-derived lexemes and still not exhibit significant structural changes in their grammars. A two-year-old Mam child growing up with intense pressure to use Spanish exhibited changes to verb, existential, and negation constructions that were not evident in the language of the other children. Negation appears to be an especially sensitive indicator of such change. Almost all of the Mayan children used the Spanish form no in response to yes/no questions and commands. A detailed comparison of the contexts of negation marking showed that NOR and his family had generalized the Spanish negation marker no to existential, potential, and other contexts, whereas WEN and the children acquiring other Mayan languages restricted their use of Spanish negation to discourse contexts alone.

The incorporation of Spanish grammatical features into the Mayan languages remains relatively undocumented. Dictionaries of Mayan languages occasionally list a few verbs that have been derived from Spanish, and these entries provide examples of the strategies that Mayan languages use to incorporate nouns and verbs. In an era of rapid language displacement, linguists need to document the many ways in which language contact changes grammatical structure. Such changes provide important insight into the nature of Mayan grammar by showing how the underlying grammatical structure accommodates new grammatical elements.

\section{REFERENCES}

Aulie, H. Wilbur, and Evelyn W. De Aulie. 1978. Diccionario Ch'ol. Re-edited by Emily F. Scharfe de Stairs, 1996. Mexico: Instituto Lingüístico de Verano.

Brown, R. McKenna. 1998. Case study two: San Antonio Aguas Calientes and the Quinizilapa Valley. The Life of Our Language: Kaqchikel Maya Maintenance, Shift, and Revitalization, ed. Susan Garzon et al., pp. 101-28. Austin: University of Texas Press.

Collins, Wesley M. 2005. Codeswitching avoidance as a strategy for Mam (Maya) linguistic revitalization. IJAL 71:239-76.

England, NoRa. 1983. A Grammar of Mam, a Mayan Language. Austin: University of Texas Press.

Furbee, N. Louanna. 2000. Prestige, power, and potential for language shift: The intrusion of Spanish into Tojolab'al Maya. Languages in Contact, ed. Dicky Gilbers, John Nerbonne, and Jos Schaeken, pp. 99-103. Amsterdam: Rodopi.

Garzon, Susan. 1998. Case study three: San Juan Comalapa. The Life of Our Language: Kaqchikel Maya Maintenance, Shift, and Revitalization, ed. Susan Garzon et al., pp. 129-54. Austin: University of Texas Press.

Grosjean, Françors. 1982. Life with Two Languages: An Introduction to Bilingualism. Cambridge, Mass.: Harvard University Press. 
$\rightarrow$ Gross, Steven. 2000. When two become one: Creating a composite grammar in creole formation. International Journal of Bilingualism 4:59-80.

Harris, Alice C., and Lyle Campbell. 1995. Historical Syntax in Cross-Linguistic Perspective. Cambridge: Cambridge University Press.

Heinze, Ivonne L. 2004. Kaqchikel and Spanish language contact: The case of bilingual Mayan children. Ph.D. dissertation, University of Kansas. <http://hdl.handle.net/1808/7986>.

Kaufman, Terrence. 1976. Proyecto de Alfabetos y Ortografias para Escribir las Lenguas Mayances. Guatemala: Ministerio de Educación.

. 1990. Algunos rasgos estructurales de los idiomas Mayances. Lecturas sobre la lingüística maya, ed. N. England and S. Elliott, pp. 59-114. Antigua: CIRMA.

Keller, Kathryn C., and Plácido Luciano G. 1997. Diccionario Chontal de Tabasco. Tucson: Summer Institute of Linguistics.

Maldonado Andrés, Juan; Juan Ordóñez Domingo; and Juan Ortiz Domingo. 1986. Diccionario Mam. Guatemala: Universidad Rafael Landívar.

Mondloch, James L. 1978. Basic Quiche Grammar. Albany, N.Y.: Institute for Mesoamerican Studies.

$\rightarrow$ Pye, C. 1992. Language loss among the Chilcotin. International Journal of the Sociology of Language 93:75-86.

Pye, C.; D. Ingram; And H. List. 1987. A comparison of initial consonant acquisition in English and Quiché. Children's Language, vol. 6, ed. Keith Nelson and Anne van Kleeck, pp. 175-90. Hillsdale, N.J.: Erlbaum.

$\rightarrow$ Redlinger, W., And T. PARk. 1980. Language mixing in young bilinguals. Journal of Child Language 7:337-52.

Winford, DonAld. 2003. An Introduction to Contact Linguistics. Malden, Mass.: Blackwell. 